ORNL/TM-2016/181

CRADA/NFE-15-05651

\title{
Investigation of Thermo-Magnetic Processing in Application to Heavy Duty Truck Suspension Components
}

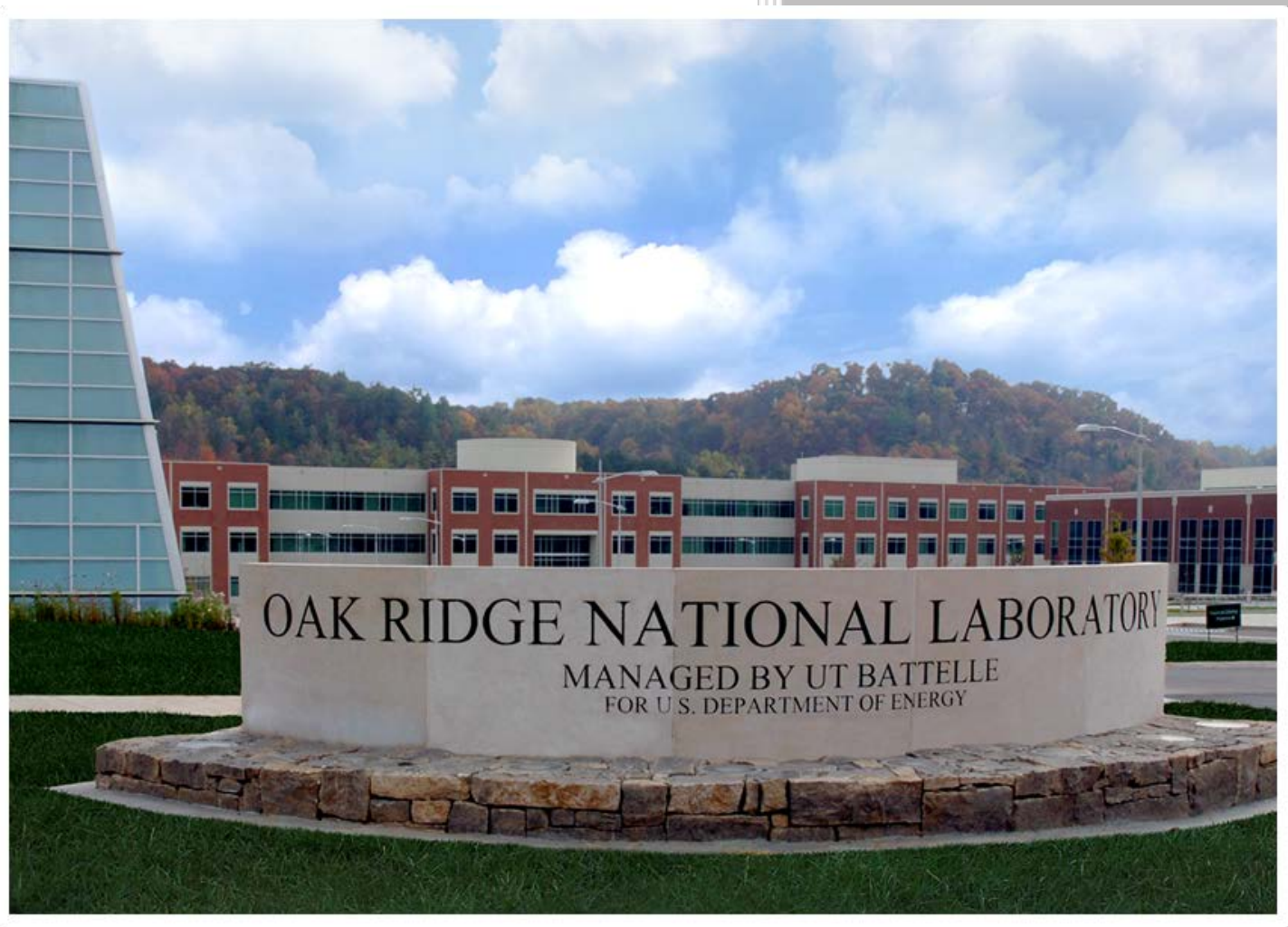

CRADA FINAL REPORT NFE-15-05651
Kurt Makiewicz, Hendrickson ATG
Approved for Public Release. Distribution is Unlimited.
April 19, 2016 


\title{
DOCUMENT AVAILABILITY
}

Reports produced after January 1, 1996, are generally available free via US Department of Energy (DOE) SciTech Connect.

Website http://www.osti.gov/scitech/

Reports produced before January 1, 1996, may be purchased by members of the public from the following source:

\author{
National Technical Information Service \\ 5285 Port Royal Road \\ Springfield, VA 22161 \\ Telephone 703-605-6000 (1-800-553-6847) \\ TDD 703-487-4639 \\ Fax 703-605-6900 \\ E-mail info@ntis.gov \\ Website http://www.ntis.gov/help/ordermethods.aspx
}

Reports are available to DOE employees, DOE contractors, Energy Technology Data Exchange representatives, and International Nuclear Information System representatives from the following source:

Office of Scientific and Technical Information

PO Box 62

Oak Ridge, TN 37831

Telephone 865-576-8401

Fax 865-576-5728

E-mail reports@osti.gov

Website http://www.osti.gov/contact.html

This report was prepared as an account of work sponsored by an agency of the United States Government. Neither the United States Government nor any agency thereof, nor any of their employees, makes any warranty, express or implied, or assumes any legal liability or responsibility for the accuracy, completeness, or usefulness of any information, apparatus, product, or process disclosed, or represents that its use would not infringe privately owned rights. Reference herein to any specific commercial product, process, or service by trade name, trademark, manufacturer, or otherwise, does not necessarily constitute or imply its endorsement, recommendation, or favoring by the United States Government or any agency thereof. The views and opinions of authors expressed herein do not necessarily state or reflect those of the United States Government or any agency thereof. 
ORNL/TM-2016/181

CRADA/NFE-15-05651

Materials Science and Technology Division Advanced Manufacturing Office

\title{
Investigation of Thermo-Magnetic Processing in Application to Heavy Duty Truck Suspension Components
}

\author{
Authors \\ Kurt Makiewicz, Hendrickson ATG \\ Theodore Yurek, Hendrickson ATG \\ Brian Farrell, Hendrickson ATG \\ Aaron Youril, Hendrickson ATG \\ Gerard M. Ludtka, ORNL
}

Date Published:

April 19, 2016

\author{
Prepared by \\ OAK RIDGE NATIONAL LABORATORY \\ Oak Ridge, Tennessee 37831-6283 \\ managed by \\ UT-BATTELLE, LLC \\ for the \\ US DEPARTMENT OF ENERGY \\ under contract DE-AC05-00OR22725
}

Approved for Public Release. Distribution is Unlimited. 


\section{CONTENTS}

CONTENTS
LIST OF FIGURES
ACKNOWLEDGEMENTS.
ABSTRACT
DUTY TRUCK SUSPENSION COMPONENTS PROCESSING IN APPLICATION TO HEAVY
2. PARTNER BACKGROUND




\section{LIST OF FIGURES}

Figure 1. (a) Hardness check in as hardened condition. (b) Hardness traverses after tempering on surface along length

Figure 2. OD of (a) production and (b) ORNL baseline both showing tempered martensite.................. 3

Figure 3. Tempered Martensite found in sub-OD for (a) Production baseline and tempered martensite

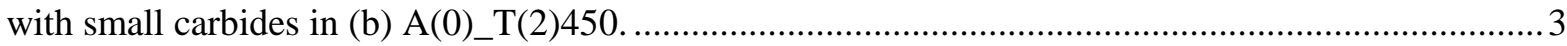




\section{ACKNOWLEDGEMENTS}

This CRADA NFE-15-05651 was conducted as a Technical Collaboration project within the Oak Ridge National Laboratory (ORNL) Manufacturing Demonstration Facility (MDF) sponsored by the US Department of Energy Advanced Manufacturing Office (CPS Agreement Number 24761).

Opportunities for MDF technical collaborations are listed in the announcement "Manufacturing Demonstration Facility Technology Collaborations for US Manufacturers in Advanced Manufacturing and Materials Technologies” posted at http://web.ornl.gov/sci/manufacturing/docs/FBO-ORNL-MDF2013-2.pdf. The goal of technical collaborations is to engage industry partners to participate in shortterm, collaborative projects within the Manufacturing Demonstration Facility (MDF) to assess applicability and of new energy efficient manufacturing technologies. Research sponsored by the U.S. Department of Energy, Office of Energy Efficiency and Renewable Energy, Advanced Manufacturing Office, under contract DE-AC05-00OR22725 with UT-Battelle, LLC. 



\begin{abstract}
Thermomagnetic processing (TMP) was examined as a methodology for increasing transformation rate during heat treatment in steel tubes. Two potential benefits were investigated, reduced energy consumption and improved mechanical properties. It is possible to reduce energy consumption with TMP by allowing tempering at lower temperatures and shorter times. Improved mechanical properties are possible by allowing a more copious distribution of fine carbides during tempering of martensite. Improved mechanical properties are also possible by quenching under a magnetic field after austenitization by formation of martensitic twins.

The experiments in this work allowed for the following conclusions: the samples could not be quenched fast enough to transform the entire wall thickness to martensite; the knee of the Continuous Cooling Curve (CCT) curve was shifted to the left when quenching following austenitizing in a magnetic field. The magnetic field during tempering did enhance the kinetics and allowed fine carbides to form. Since the through wall thickness was not hardened, the bulk mechanical properties were unaffected by the magnetic field. Hardness measurements after hardening showed that hardening in a magnetic field $>0.5 \mathrm{~T}$ resulted in a significant reduction in hardness. Combined with the inadequate cooling rate it was not possible to properly harden the samples. Tempering at $600^{\circ} \mathrm{C}$ without a magnetic field resulted in no formation of carbides, but tempering at $600^{\circ} \mathrm{C}$ and $450^{\circ} \mathrm{C}$ with a $1-2 \mathrm{~T}$ field resulted in carbide formation in all samples.
\end{abstract}

\title{
1. INVESTIGATION OF THERMO-MAGNETIC PROCESSING IN APPLICATION TO HEAVY DUTY TRUCK SUSPENSION COMPONENTS
}

This phase 1 technical collaboration project (MDF-TC-2015-070) was begun on March 30, 2015 and was completed on February 29, 2016. Hendrickson is a large business.

\subsection{BACKGROUND}

The majority of products for heavy duty truck suspensions and components require forming and joining steel components. Today most manufacturers use higher performing steels that are more expensive in order to increase performance and reduce weight. There are three ways that costs can be lowered to stay competitive against low cost foreign sourced parts. They are reducing processing cost, reducing material cost, and using less material. The TMP technology at Oak Ridge National Laboratory (ORNL) provides opportunities in each of these areas. The focus of this study is the 5" steel tube that is heat treated to improve its mechanical properties. The tubes feature ends that are friction welded, heat treated, and tempered. Increased mechanical properties and reduced energy consumption were the primary objectives of the study.

\subsection{TECHNICAL RESULTS}

A parameter matrix was developed for the tubes to test various austenitization and tempering magnetic fields and tempering temperatures. The austenitization B field was varied between 0 0.5Tesla (T), the tempering B field was varied between $0-2 \mathrm{~T}$, and the tempering temperature was 
varied between $450^{\circ} \mathrm{C}$ and $600^{\circ} \mathrm{C}$. The temper time was not modified. The following naming convention was used to describe the treatment applied to the samples. $\mathbf{A}(\mathbf{X}) \_\mathrm{T}(\mathbf{Y}) \mathbf{Z Z Z Z}$ with $\mathbf{X}$ being the austenitization B field, $\mathbf{Y}$ being the tempering B field, and $\mathbf{Z}$ being the temper temperature.

Hardness was checked at ORNL following austenitization and quench to verify that the samples hardened sufficiently. Following hardening only two points were checked. Figure 1a shows the data for $0 \mathrm{~T}$ and $0.5 \mathrm{~T}$ field strengths. The austenitization field strength was limited to $0.5 \mathrm{~T}$ because it was found that higher fields lowered the hardness. It is believed that this was occurring because the knee of the CCT curve was shifted to the left by the magnetic field.
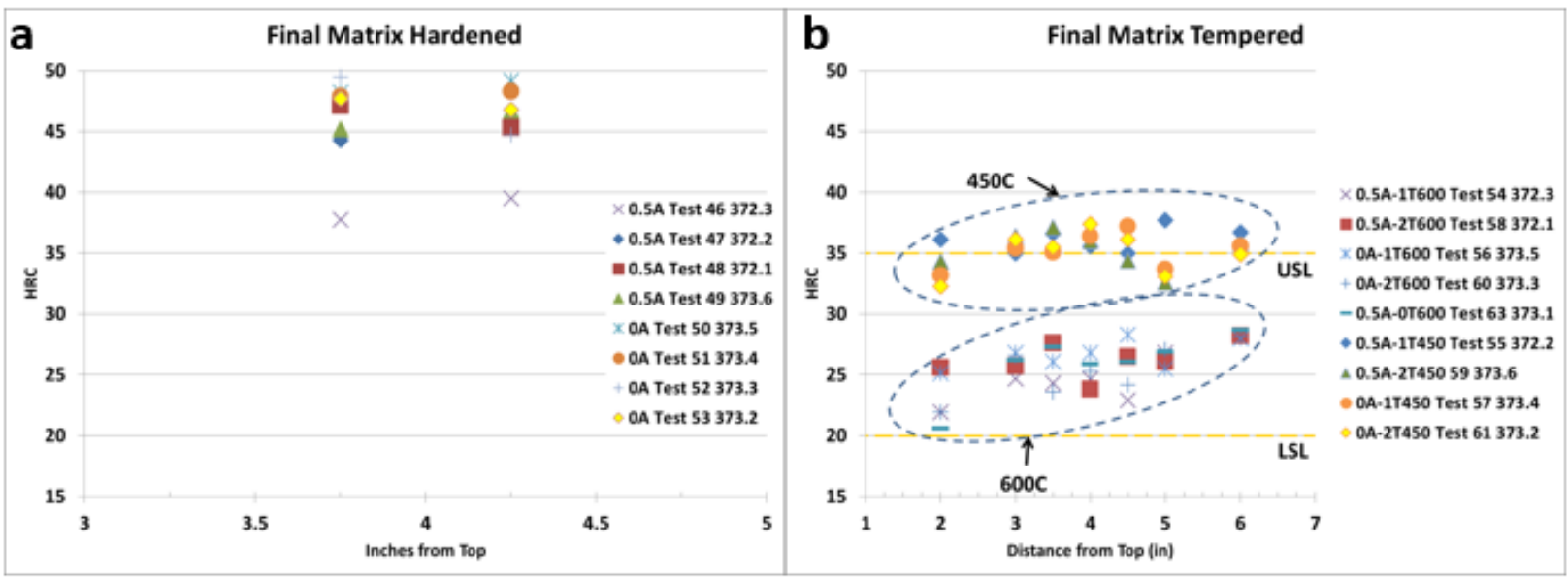

Figure 1. (a) Hardness check in as hardened condition. (b) Hardness traverses after tempering on surface along length.

Figure 1b shows the hardness data collected at ORNL following tempering. The baseline value for the production spec can be seen with an upper spec limit and lower spec limit. A clear demarcation is seen between the tests at $450^{\circ} \mathrm{C}$ and $600^{\circ} \mathrm{C}$. The temperature appears to be the driving factor in the hardness since parts at $1 \mathrm{~T}$ and $2 \mathrm{~T}$ are seen in both groups.

Tensile testing was performed on samples extracted from the processed tubes. The mechanical properties did not show a significant change when processed with the magnetic field. This is likely because the bulk material did not transform into martensite.

Optical microscopy was performed on specimens extracted from the mid-length of the tubes. The specimens were mounted such that the through-wall thickness could be analyzed. The images below are representative of what was observed through all of the specimens. The microstructure near the outer diameter (OD) for both the production and ORNL baseline was tempered martensite (Figure 2). Moving toward the inner diameter (ID) of the tube, inadequate cooling with the ORNL equipment resulted in ferrite and pearlite.

The presence of tempered martensite only near the OD shows that the cooling rate was not fast enough to deeply penetrate the wall thickness. This finding explains the lack of mechanical property change on samples with the magnetic field. 

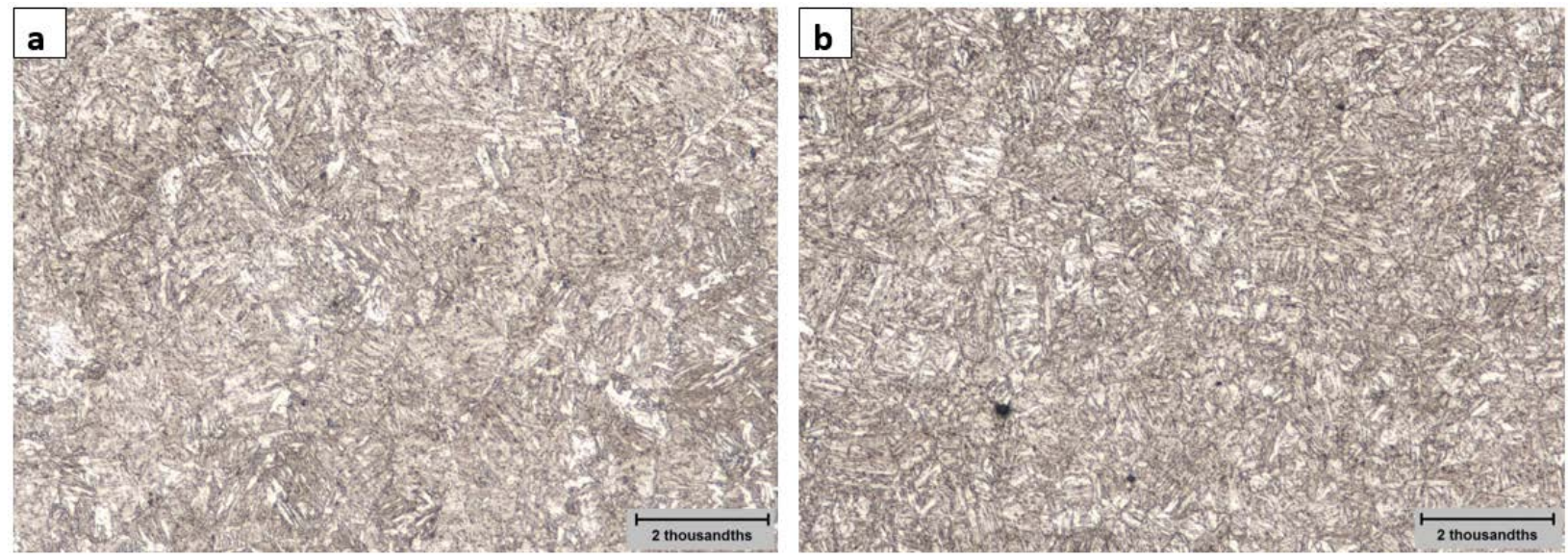

Figure 1. Outer diameter of (a) production and (b) ORNL baseline both showing tempered martensite.

Scanning Electron Microscopy (SEM) analysis revealed small precipitates in samples that had been tempered in the magnetic field. In Figure 3a the baseline sample is compared to a sample tempered at $2 \mathrm{~T}$ with a lower tempering temperature. The baseline shows tempered martensite without any small precipitates. Figure 3b shows tempered martensite with small particles that are assumed to be precipitates.
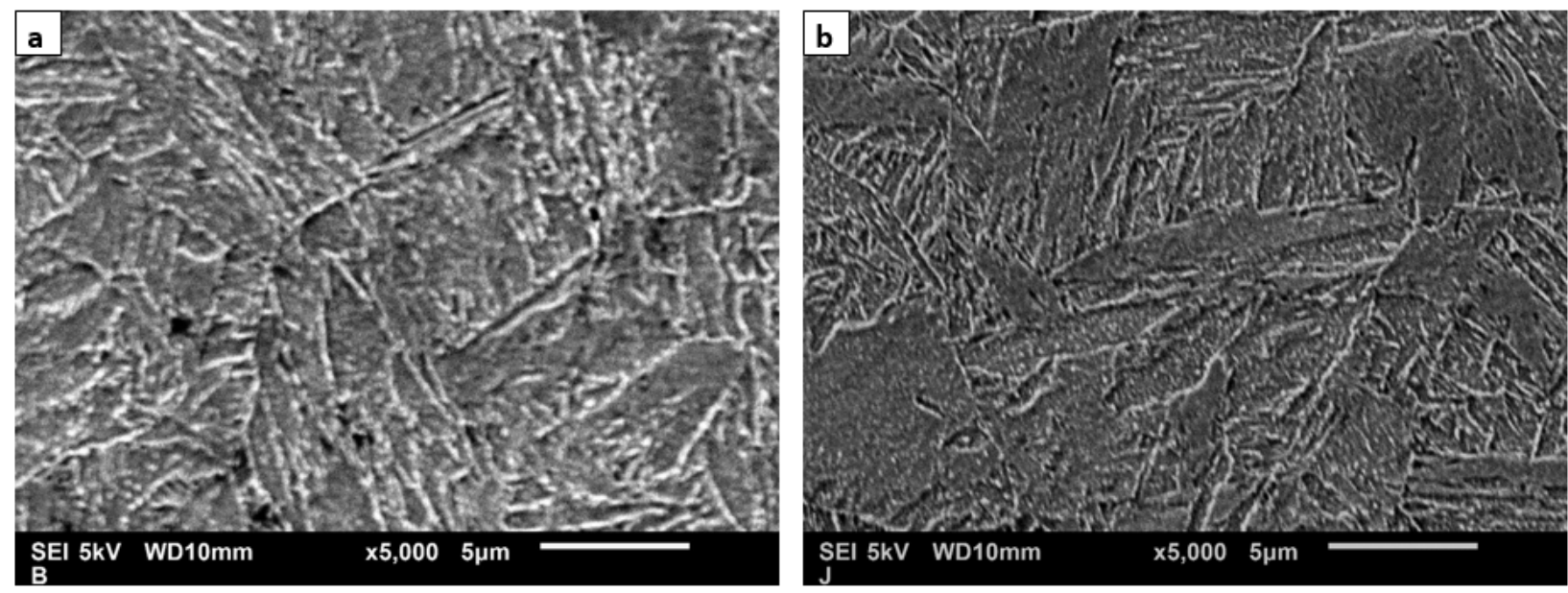

Figure 2. Tempered Martensite found in sub-OD for (a) Production baseline and tempered martensite with small carbides in (b) A(0)_T(2)450.

\subsection{DISCUSSION}

The lack of improvement in mechanical properties was supported by the micrographs of the bulk material. The optical micrographs show that the martensitic transformation only occurred near the OD of the tube. If the cooling rate from the austenitization temperature were increased then it would be possible to get more martensite through the wall thickness. However, as shown for the production process sample, it would still not be possible to get $100 \%$ martensite through the thickness. This is because the part is thick enough that the cooling is diffusivity limited when cooling the outer diameter only. If the sample were thinner or a process could cool the inner diameter at the same time it would be possible to have $100 \%$ martensite upon quenching and tempered martensite following tempering. 
The hardness tests following austenitization and quench at 0T, 0.5T, 1T, and $2 \mathrm{~T}$ show a clear reduction in hardness with increasing magnetic field strength. This indicates that the magnetic field is enhancing the kinetics of the austenite decomposition. This means that while holding the cooling rate constant the increasing magnetic field made it easier for ferrite, pearlite, and bainite to form. This provides evidence that the knee of the CCT curve was shifted to the left. To get martensite anywhere in the sample the cooling rate would have to be increased well beyond $100^{\circ} \mathrm{C} / \mathrm{s}$.

Close examination of the sub-OD with the SEM revealed small particles in samples tempered with the magnetic field. These particles were also seen in the $450^{\circ} \mathrm{C}$ temper samples. The particles were not observed in any samples tempered without the field. This shows that the field was able to enhance the kinetics of the tempering process. Since the through thickness did not show martensite, it is not currently known if the particles are beneficial or detrimental. The particles are assumed to be carbides but the specific type of carbide is not known.

The claim that TMP could reduce energy consumption was not proven with this experiment. This is because the tempering time with this material is short. The temper time in this experiment was not modified, and so the energy required with the samples saturated was actually higher. With the sample saturated during tempering it took nearly $2,000 \mathrm{KW}^{*}$ s more energy to bring the temperature to $600^{\circ} \mathrm{C}$. To reach the $450^{\circ} \mathrm{C}$ temperature it took nearly $1,000 \mathrm{KW}^{*}$ s more energy. Even if the tempering dwell time could be eliminated, the energy saved would only be around $100 \mathrm{KW}^{*}$ s. The tempering time for this material is just not long enough to see a benefit from reduced time.

\subsection{CONCLUSIONS}

This project demonstrated that large tubes could be processed with the ORNL TMP equipment. However, the quench system could not match the cooling rate capable with the production system. This lower cooling rate limited the formation of martensite to the region near the OD of the tube. This limitation also meant that the bulk material properties were not affected by the magnetic field. The knee of the CCT curve was demonstrated to shift leftward during austenitization and quench with magnetic fields of $0.5 \mathrm{~T}, 1 \mathrm{~T}$, and $2 \mathrm{~T}$. This was confirmed by lower hardness values with increasing magnetic field. Magnetic fields of 1T and 2T applied during tempering enhanced the martensite decomposition and promoted the formation of small particles. Since the transformation did not occur through the wall thickness the current work could not determine if these particles were beneficial or detrimental. Further hardness testing in the regions containing these particles could give insight into their effect. A more robust investigation of these particles would involve creating mechanical test samples with a homogeneous microstructure. 


\section{PARTNER BACKGROUND}

Hendrickson, a Boler company, is a premier global manufacturer and supplier of truck and tractor suspensions; trailer suspensions, controls and non-integrated suspension components; truck and trailer lift axles; bumpers and trim components; and truck, tractor and trailer springs to the commercial transportation industry. After 100 years in the forefront of the industry, Hendrickson continues to pioneer innovative ride solutions for heavy-duty commercial vehicles. 